\title{
Comparative study of low dose aspirin versus combination of low dose aspirin and low molecular weight heparin in idiopathic recurrent pregnancy loss
}

\author{
S. Bhanu Rekha ${ }^{1}$, K. Sharath Chandra ${ }^{2 *}$ \\ ${ }^{1}$ Department of Obstetrics and Gynecology, ${ }^{2}$ Department of Dermatology, SVS Medical College, Mahabubnagar, \\ Telangana, India
}

Received: 21 December 2019

Accepted: 30 December 2019

*Correspondence:

Dr. K. Sharath Chandra,

E-mail: drsharath2k@yahoo.co.in

Copyright: $\odot$ the author(s), publisher and licensee Medip Academy. This is an open-access article distributed under the terms of the Creative Commons Attribution Non-Commercial License, which permits unrestricted non-commercial use, distribution, and reproduction in any medium, provided the original work is properly cited.

\section{ABSTRACT}

Background: To compare the role of low dose aspirin versus combination of low dose aspirin and low molecular weight heparin in idiopathic recurrent pregnancy loss and assess the effectiveness of low dose aspirin and low molecular weight heparin in having a better obstetric outcome.

Methods: This study was conducted in a private hospital in Mahabubnagar from June 2017 to May 2019. A total of 80 pregnant ladies who had previous 2 and or more pregnancy losses in the early (before 20 weeks) or late (after 20 weeks) pregnancy period was included in the study. 80 pregnant women with idiopathic/unexplained recurrent pregnancy loss were properly evaluated in regard to the history of previous period of gestation of loss, previous scans in regard to documentation of fetal pole and gestation, cardiac activity, anomaly scan and growth scan and any special investigations in previous pregnancies and present pregnancy.

Results: A total 80 pregnant women with previous 2 and more unexplained pregnancy losses who were evaluated and found negative with major causes of pregnancy losses half of them (40) were treated with low dose aspirin alone and the other 40 women were treated with a combination of low dose aspirin $(75 \mathrm{mg})$ and low molecular weight Heparin $(20 \mathrm{mg})$ daily low molecular weight heparin till term. The aspirin alone group had $82.5 \%$ live birth rate and the combination group had $92.5 \%$ live birth rate which is quite satisfactory and more than the Aspirin alone group.

Conclusions: Use of combination of low dose aspirin and low molecular weight heparin seems to be a good choice of drugs in treating the unexplained recurrent pregnancy losses than low dose aspirin alone.

Keywords: Low dose aspirin, Low molecular weight heparin, Recurrent pregnancy loss

\section{INTRODUCTION}

Pregnancy is usually a safe journey with good outcome. In few cases unfortunately have an unpredictable bad outcome in the form of abortions or preterm labours or still births. This leads to mental agony to the aspiring mother to be as well as the entire family. ${ }^{1}$ After such recurring pregnancy losses for 2 and or more times, there is lot of anxiety to regarding to the entire family as well as expectations from the treating doctors. ${ }^{2}$ Women with such previous pregnancy losses should be evaluated properly with the history of pregnancy loss in respect to the gestational age, previous scans showing viable fetus, any infections in the past pregnancies and present, hormonal evaluations like thyroid levels, gestational diabetes screening, anti-phospholipid syndrome and protein $\mathrm{C}$ and protein $\mathrm{S}$ deficiencies, karyotyping of both partners as well as previous products of conception was subjected to Karyotyping or Microarray, MRI of the uterus to rule out any uterine anomaly, preeclampsia, eclampsia apart from the routine antenatal investigations. ${ }^{3}$ In a town like Mahabubnagar with its feeding districts, 
many a times our patients can't afford beyond Microarray and all the above-mentioned tests and any further analysis in respect to evaluation of recurrent pregnancy losses (RPL) so as to guide them during the next pregnancy., ${ }^{4,5}$ Hence there arises a need for managing these set of patients with minimum special investigations along with the routine antenatal tests to rule out the cause and start safe and empirical treatment to lessen the recurrence and anxiety associated with the current ongoing pregnancy. ${ }^{6,7}$

\section{Objectives}

- To identify, investigate and categorise the patients presenting with bad obstetric outcomes recurrently over a period of 2 years.

- To select patients with unexplained or idiopathic recurrent pregnancy losses randomly and group into Group 1 who would be treated with low dose aspirin (75 mg) alone and Group 2 who would be treated with a combination of low dose aspirin $(75 \mathrm{mg})$ and low molecular weight heparin $(20 \mathrm{mg})$ daily till term.

- To compare both group patients with RPL and after evaluating with major identifiable causes and if found negative with common causes of RPL to start treatment as early as pregnancy confirmation with low dose aspirin $(75 \mathrm{mg}$ ) daily once till 36 weeks and lowest possible dose of low molecular weight heparin $(20 \mathrm{mg})$ daily till term.

\section{METHODS}

This study was conducted in a private hospital from June 2017 to May 2019 over a period of 2 years. The patients who had 2 and or more pregnancy losses in the previous antenatal period were grouped as early pregnancy losses (before 20 weeks gestation) and late pregnancy losses and who were presently pregnant and have registered in our antenatal clinic in $1^{\text {st }}$ trimester were properly evaluated and after finding negative for maternal infections, gestational diabetes, thyroid problems, uterine malformations, any karyotype or microarray assay, APLA syndrome, protein $\mathrm{C}$ or $\mathrm{S}$ deficiency, previous medical disorders or preeclampsia, eclampsia were pooled into 2 groups randomly. 40 unexplained RPL patients in Group 1 were started with low dose aspirin (75 $\mathrm{mg}$ ) daily once till 36 weeks and 40 patients of unexplained RPL in Group 2 who were treated with low dose aspirin $(75 \mathrm{mg}$ ) and low molecular weight heparin (20 mg) daily till term as soon as pregnancy was confirmed. Both the group patients were randomly selected and in this process of undergoing the study, patients were counselled and due ethical standards were maintained as to the information, procedure and secrecy. The data was pooled and results were formed and arrived at conclusion regarding the benefit of these two drugs in isolated use or in combination for the unknown etiology of RPL.

Present study was carried out in a private hospital in Mahabubnagar, Telangana, India from June 2017 to May
2019. Over an average of 800 antenatal OPD monthly and 7000 annual OPD.

\section{Inclusion criteria}

A total 80 pregnant women with idiopathic RPL were included in the present study who fitted into the following criteria

- $\quad$ These women had previous 2 and or more pregnancy losses varying from gestational age of 6 and more week gestation

- Most of these women had early fetal viability scans of their previous pregnancies

- These women were also negative for uterine malformations, genetic analysis, gestational diabetes, APLA, protein $\mathrm{C}$ and $\mathrm{S}$ deficiency, thyroid abnormalities, medical causes, preeclampsia or eclampsia in relevance to history and investigations

- Most of these women could get karyotyping barring 3 women and all the others had normal karyotyping except 1 who had banding in 18th chromosome

- All the 80 patients were enrolled in present pregnancy and were investigated and classified randomly into Group 1 patients consisting of 40 patients treated with $75 \mathrm{mg}$ of aspirin daily once till 36 weeks of gestation and Group 2 of 40 patients who were treated with a combination of low dose aspirin (75 mg) till 36 weeks and low molecular weight heparin $20 \mathrm{mg}$ on daily till term.

\section{Exclusion criteria}

- Abnormal karyotypes of each partner, uterine and/or cervical anatomical disorders on pelvic ultrasonography or hysteroscopy, abnormal ovaries function, abnormal endocrine tests, GCT abnormal and antiphospholipid syndrome.

\section{Statistical analysis}

The results analyzed by SPSS (version 15) and they were tested by chi-square test. The results were significant in $\mathrm{P}$ $>0.05$.

\section{RESULTS}

Out of 80 pregnant women with 2 and or more previous pregnancy losses together in both the groups who were fitting all the inclusion criteria of unexplained recurrent pregnancy losses of 7000 antenatal OPD the incidence was accounting to $1.1 \%$. Age group of majorities of women were in the group 18-36 years. All the 80 pregnant ladies irrespective of their Groups in their first antenatal visit were asked in detail about the previous antenatal losses and investigations past and present to rule out the major etiology of recurrent pregnancy losses like gestational diabetes, APLA, thyroid disorders, karyotyping or rarely protein $\mathrm{C}$ or protein $\mathrm{S}$ deficiency or 
uterine malformation. Group 1 patients were counselled regarding the use of low dose aspirin $(75 \mathrm{mg})$ daily and Group 2 patients were asked to take Low dose aspirin (75 $\mathrm{mg}$ ) daily till 36 weeks and low molecular weight heparin $(20 \mathrm{mg})$ till term after counselling regarding the safety profile of the drugs and unpredictable outcome in spite of the best monitoring. In Group 2 patients LDA and Low molecular weight heparin was given $20 \mathrm{mg}^{2}$ daily till term inspite of lack of substantial gross evidence of any microthrombi or any such vascular lesion leading to fetal demise in both early and late pregnancy losses in previous pregnancies. Consent was obtained and the patients were duly registered for the combination treatment along with the routine antenatal supplements. These patients were monitored routinely and on nearing 36 weeks, low dose Aspirin was discontinued in both the group patients and low molecular weight heparin was continued till term or onset of delivery in only Group 2 patients. The results were analysed in both groups regarding the continuation of pregnancy till term and the obstetric outcome as to maternal and fetal wellbeing irrespective of the mode of delivery i.e abdominal or vaginal as it was on obstetric demand. In Group 1 of LDA use patients, 33 patients $(82.5 \%)$ out of 40 continued pregnancy till term and had a good obstetric outcome regarding maternal and fetal wellbeing, 3 patients $(7.5 \%)$ had abortions before 12 weeks and 1 patient $(2.5 \%)$ had IUD at 15 weeks GA, 1 patient $(2.5 \%)$ had fetal loss at 29 weeks due to PPROM and 2(5\%) patients lost follow up after 32 weeks. Out of Group 2 patients with unexplained RPL where 40 pregnant women with previous pregnancy losses were given LDA and LMWH, 37 patients $(92.5 \%)$ had continued pregnancy till term and had a good outcome i.e a healthy mother who had delivered a healthy neonate by either vaginal route or abdominal route for obstetric indications alone. $1(2.5 \%)$ patient lost follow up, 1 patient $(2.5 \%)$ had spontaneous late abortion at 14 weeks gestation despite on drugs and 1 patient $(2.5 \%)$ had sudden IUD as the patient lost follow up in between and also discontinued drugs and reported with IUD (Table 1).

Table 1: Comparison of pregnancy outcomes.

\begin{tabular}{|lll|}
\hline Pregnancy outcome & Group 1 & Group 2 \\
\hline Term & 33 pts $(82.5 \%)$ & $37(92.5 \%)$ \\
\hline Early abortions & $3(7.5 \%)$ & Nil \\
\hline Late abortions & $1(2.5 \%)$ & $1(2.5 \%)$ \\
\hline Late pregnancy loss & $2(5 \%)$ & $1(2.5 \%)$ \\
\hline Lost follow up & $1(2.5 \%)$ & $1(2.5 \%)$ \\
\hline
\end{tabular}

\section{DISCUSSION}

Recurrent pregnancy loss occurs in about $1 \%$ of couples. Many a times after ruling out all the major causes, there comes a time when there would be not much options in spite of the best of the available treatments except for the empirical treatments. One of the probable causes of unexplained RPL could be any microthrombi leading to pregnancy loss. ${ }^{8}$ Hence this study used $75 \mathrm{mg}$ of ASA and $20 \mathrm{mg}$ LMWH and monitoring their pregnancy outcomes. The most common assumption being an undetectable low-grade inflammation or micro thrombi responsible for these pregnancy losses. ${ }^{9}$ Many cochrane studies like APRIL was done to study the role of LDA in prevention of recurrent spontaneous pregnancy losses. In this study we tried to compare the use of LDA alone and combination of LDA and LMWH. ${ }^{10}$

This study was conducted on in unexplained RPL pregnant ladies over a period of 2 years who had recurrent pregnant loss either early or late and were treated with LDA till 36 weeks alone (Group 1) and LDA with daily $20 \mathrm{mg}$ LMWH5 continued till term. ${ }^{11}$ The outcome in both the groups were analysed. Out of pregnant women in study Group 1, 33 women continued till term. 3 pregnant women landed with early abortions (before 12 weeks), 1 patient had IUD at 15 weeks and 2 patients lost follow up after 20 weeks. ${ }^{12}$ In Group 2, 37 woman had a safe term deliveries and had a healthy neonate, 1 patient had late abortion at 14 weeks, 1 patient landed up with Intrauterine fetal death at 30 weeks and was found to have stopped treatment for the last 6 days before landing up with IUFD and 1 patient lost follow up. ${ }^{13}$ This gives us $82.5 \%$ and $92.5 \%$ live birth rates in Group 1 and Group 2 respectively which is similar to the study by Enrique et al, which showed a higher birth rate too. But in comparison to Group 1, the Group 2 patients had much better outcomes in terms of continuation till term and good obstetric outcome. Combination of LDA along with LMWH proved superior in our cases similar to the study done by Mak A et al who too had better outcomes of heparin and aspirin which included APLA positive cases. ${ }^{14}$

Though this study has very small inconspicuous data for coming to any conclusions, but has given a good scope for large multicentric trial of using low dose aspirin (75 $\mathrm{mg}$ ) daily 7 and low molecular weight heparin $(20 \mathrm{mg})$ daily till term in patients who have recurrent pregnancy losses with no detectable etiology and hence as treated empirically as unexplained RPL. 15

\section{CONCLUSION}

Recurrent pregnancy loss both early and late continues to be an unpleasant issue for both the patient and the treating doctor, especially those cases whom have diagnosed negative with the major known detectable causes. Despite trying the best to investigate, there comes a time with no major detectable etiology. LDA and LMWH still gives an optimistic plausible result much more in comparison to LDA alone in unexplained RPL though large multicentric trials globally is needed to substantiate the use of LDA along with LMWH in unexplained RPL for a better obstetric outcome.

Funding: No funding sources

Conflict of interest: None declared 
Ethical approval: The study was approved by the Institutional Ethics Committee

\section{REFERENCES}

1. Greer IA, Low molecular weight heparin for pregnancy complications. The Lancet. 2016;26:25702.

2. Yuksel H, Kayatas S, Boza AT, Api M, Ertekin AA, Cam C. Low molecular weight heparin use in unexplained recurrent miscarriage. Pak J Med Sci. 2014;30(6):1232-7.

3. Pasquier E, de Saint Martin L, Bohec C, Chauleur C, Bretelle F, Marhic G, Le Gal G, et al. Enoxaparin for prevention of unexplained recurrent miscarriage: a multicenter randomized double-blind placebocontrolled trial. Blood. 2015;125(14):2200-5.

4. Bose P, Black S, Kadyrov M, Weissenborn U, Neulen J, Regan L, et al. Heparin and aspirin attenuate placental apoptosis in vitro: implications for early pregnancy failure. Am J Obstet Gynecol. 2005;192(1):23-30.

5. Badawy AM, Khiary M, Sherif LS, Hassan M, Ragab A, Abdelall I. Low-molecular weight heparin in patients with recurrent early miscarriages of unknown aetiology. J Obstet Gynaecol. 2008;3:2804.

6. Mak A, Cheung MW, Cheak AA, Ho RC. Combination of heparin and aspirin is superior to aspirin alone in enhancing live births in patients with recurrent pregnancy loss and positive antiphospholipid antibodies: a meta-analysis of randomized controlled trials and meta-regression. Rheumatol. 2009;49(2):281-8.

7. Demers $S$, The use of aspirin durimg pregnancy. Am J obstet Gynecol. 2013;208(2):161-2.

8. Mitić G, Novakov Mikić A, Povazan L, Mitreski A, Kopitović V, Vejnović T. Thromboprophylaxis implementation during pregnancy in women with recurrent foetal losses and thrombophilia. Med Pregl. 2011;64:471-5.

9. Kaandorp SP, Goddijn M, van der Post JA, Hutten BA, Verhoeve HR, Hamulyák K, et al. Aspiri plus heparin or aspirin alone in women with recurrent miscarriage. N Engl J Med. 2010;362:1586-96.

10. Infante-Rivard C, David M, Gauthier R, Rivard GE. Lupus anticoagulants, anticardiolipin antibodies, and fetal loss a case-control study. N Engl J Med. 1999;325:1063-6.

11. Lockshin MD. Pregnancy loss in the antiphospholipid syndrome. Thromb Haemost. 1999;82:641-8.

12. Greer IA. Antithrombotic treatment for recurrent pregnancy loss?. J Thromb Haemost. 2011;9:302-5.

13. Kaandorp S, Di Nisio M, Goddijn M, Middeldorp S. Aspirin or anticoagulants for treating recurrent pregnancy loss in women without antiphospholipid syndrome. Cochrane Database Syst Rev. 2009;(1):CD004734.

14. Laude I, Rongières-Bertrand C, Boyer-Neumann C, Wolf M, Mairovitz V, Hugel B, et al. Circulating procoagulant microparticles in women with unexplained pregnancy loss: a new insight. Thromb Haemost. 2001;85:18-21.

15. McNamee K, Dawood F, Farquharson RG. Thrombophilia and early pregnancy loss. Best Pract Res Clin Obstet Gynaecol. 2012;26:91-102.

Cite this article as: Rekha SB, Chandra KS.

Comparative study of low dose aspirin versus combination of low dose aspirin and low molecular weight heparin in idiopathic recurrent pregnancy loss. Int J Reprod Contracept Obstet Gynecol 2020;9:512-5. 